\title{
ECOLALIA E MÚSICA: A LINGUAGEM NO AUTISMO
}

\author{
Echolalia and music: the language in autism
}

\author{
Glória Maria Monteiro de CARVALHO ${ }^{1}$ \\ Maria de Fátima Vilar de MELO
}

Resumo: Pretendemos abordar a ecolalia no autismo como uma manifestação da resistência oferecida pelo corpo da criança à perda do som, isto é, à implantação do significante, partindo da posição psicanalítica segundo a qual, para se tornar falante, a criança precisa perder/esquecer/recalcar a dimensão sonora da voz e conservar o sentido, o que, entretanto, somente ocorre se essa dimensão se mantém no sujeito como inscrição significante. Nesse sentido, adotamos a proposta de que a dimensão sonora da voz do outro poderia aprisionar a criança, constituindo um obstáculo a sua trajetória linguística, mas, ao mesmo tempo, seria por meio dessa dimensão sonora que se poderia indicar uma saída para esse aprisionamento. A título de ilustração, foram discutidos alguns episódios que contêm manifestações verbais de um menino com hipótese de autismo. Propomos, então, que manifestações musicais, por exemplo, as canções, poderiam favorecer, na criança com autismo, um retorno da musicalidade da voz materna, com suas dimensões de continuidade e descontinuidade. Por sua vez, tal retorno talvez pudesse propiciar alguma ruptura na continuidade sonora incorporada por essa criança, fazendo face à resistência que seu corpo opõe à implantação do significante.

Palavras-chave | Ecolalia. Autismo. Som. Resistência. Canção.

\begin{abstract}
This work aims to approach echolalia in autism as a manifestation of resistance offered by the body of the child to sound loss, that is, the implementation of the signifier, based on the psychoanalytic view according to which, in order to become a speaker, the child needs to lose/forget/repress the sound dimension of his or her voice, as well as to maintain sense, which, however, only occurs if that dimension remains in the subject as a signifier inscription. In this sense, we adopt the proposal that the sound dimension of the other's voice could imprison the child, constituting an obstacle to his or her linguistic trajectory, but at the same time, by means of this dimension, there would be a release from such an imprisonment. For the sake of illustration, discussions were made about some episodes containing utterances of a boy with a hypothetical diagnosis of autism. We assume, then, that musical expressions, such as songs, in the child with autism, could bring about a return of the musicality of the mother's voice, with its dimensions of continuity and discontinuity. On the other hand, such a return could perhaps provide some break in the sound continuity incorporated by this child, confronting resistance from his or her body to the implementation of the signifier.
\end{abstract}

Keywords | Echolalia. Autism. Sound. Resistance. Song.

1 Carvalho. Universidade Católica de Pernambuco. Endereço eletrônico: gmmcarvalho@uol.com.br

2 Vilar de Melo. Universidade Católica de Pernambuco. Endereço eletrônico: mfvmelo@uol.com.br 
- Ecolalia e música: a linguagem no autismo

\section{Introdução}

Neste artigo ${ }^{3}$, tentaremos dar continuidade a artigo anterior (CARVALHO, 2012), em que foram discutidas as verbalizações ecolálicas de uma criança com hipótese de autismo, tendo sido indicado um movimento singular nessas verbalizações.

Pretendemos, neste momento, abordar a ecolalia no autismo como uma resistência que a criança opõe ao recalque do som, ou melhor, como uma resistência à implantação do significante em seu corpo, que, nesse caso específico, consistiria em um obstáculo ao movimento de constituição da subjetividade. Iniciamos esta abordagem destacando a proposta psicanalítica segundo a qual, para se tornar falante, a criança precisa deixar escapar - deixar perder/esquecer/recalcar - a dimensão sonora da voz e conservar o sentido, o que, entretanto, somente ocorre se essa dimensão se mantém no sujeito como inscrição significante.

Segundo Vivès (2012, p. 20), para se tornar invocante, o sujeito deve, necessariamente, tornar-se surdo à pura continuidade vocal do Outro, afirmando que: "Quem não chega a estruturar esse ponto surdo por intermédio do recalque originário se vê tomado pela voz do Outro. E quem não consegue se tornar surdo a essa voz primordial permanece indefinidamente nela suspenso, sob os seus efeitos".

Nesse sentido, diz Pommier (2004, p. 124): "O diferencial esquece o som, recalca o som do objeto quando ele se torna uma letra que participa da formação de um significante. Se digo 'lobo', vocês pensarão no animal e esquecerão a música do som ' $l o$ ' com a qual podemos cantarolar". Esse autor destaca, contudo, que uma palavra ainda continua cheia de seu valor pulsional, até que seja definida por outra palavra no ato de nomear, perdendo, desse modo, sua música.

Convém ressaltar, neste momento, a distinção feita por Lacan (1998) entre linguagem em sua função de comunicar e fala. De acordo com essa distinção lacaniana, para se tornar linguagem apta ao intento de comunicação, é exigido da fala que o som seja recalcado. Para esse autor, a fim de atender a sua função de dar informações, a linguagem tem que se neutralizar. Nesse sentido, afirma: "Vemos, pois, a antinomia imanente às relações da fala com a linguagem. À medida que a linguagem se torna mais funcional, ela se torna imprópria para a fala e, ao se nos tornar demasiadamente particular, perde sua função de linguagem" (LACAN, 1998, p. 300).

3 Este artigo faz parte do Projeto de Pesquisa "Aquisição de linguagem, música e autismo" financiado pelo CNPq. 
Mais adiante, afirma:

[...] aí podemos constatar que uma parte importante do meio fonético é supérflua para que se realize a comunicação efetivamente buscada. [...] Isso nos é altamente instrutivo, pois o que é redundância para a informação é precisamente aquilo que, na fala, faz as vezes de ressonância. (LACAN, 1998, p. 300).

Assim, as ressonâncias que são importantes na fala, segundo a concepção lacaniana, são supérfluas na linguagem comunicativa/informativa, na medida em que a função da fala é evocar e não informar. Em outras palavras, podemos dizer, de acordo com essa distinção, que, para se tornar linguagem apta a informar, é exigido da fala que o som seja esquecido/recalcado.

É nessa direção que tentaremos encaminhar a discussão indicada no título deste trabalho. No entanto, para seguirmos, consequentemente, este caminho, assumimos a concepção de corpo na perspectiva da psicanálise: trata-se, portanto, de corpo pulsional e não de organismo, não havendo equivalência entre corpo e organismo biológico ou entre corpo e sujeito psicológico. Nesse corpo, segundo Pommier (2004, p. 125), "entre as várias superfícies pulsionais, a boca é o lugar mais conflituoso", na medida em que a boca come e emite sons, sendo, neste último caso, especificada como pulsão invocante.

A esse respeito, baseamo-nos em Lemos (2008), sobretudo em seu texto "Da angústia na infância", a partir do qual é possível destacar a resistência que a criança, concebida como corpo pulsional, opõe a sua captura pelo significante. Segundo essa autora, uma tal captura não é pacífica, mas implica conflito - conflito a esperar do embate entre heterogêneos: corpo e linguagem.

Nesse enfoque, o corpo da criança resiste a sua captura simbólica, podendo essa resistência ser indicada através daquilo que escapa à captura, ou daquilo que falha, como é o caso, por exemplo, dos erros, incluindo-se tanto os erros previsíveis quanto as produções verbais insólitas. A esse respeito, podemos pensar, com fundamento em Leite (2003), que o funcionamento da linguagem como estrutura consiste numa rede de inibições e, acrescentaríamos, uma rede de inibições implantada num corpo.

Esse conflito (ou embate) entre corpo e linguagem não se dá a ver, ficando oculto se, durante a sua trajetória linguística, a criança não se depara com uma dificuldade que produza efeitos de obstáculo a essa trajetória. Tudo aconteceria, conforme realça Lemos (2008), como se a criança seguisse um percurso suave que não daria visibilidade àquele 
- Ecolalia e música: a linguagem no autismo

embate inicial o qual pode, contudo, ser indicado. No entanto, se algum obstáculo vem à tona, com ele se torna visível um corpo, ou melhor, um corpo que aparece na sua resistência oferecida à palavra, à perda do som, isto é, à implantação do significante, ou ainda, um corpo pulsional que se expressa e por isso aparece, não deixando que essas expressões se inibam, sejam esquecidas ou sejam recalcadas pela palavra.

Balbo (2004) refere-se a crianças que resistem à perda da dimensão sonora da voz materna. Trata-se, portanto, de uma resistência oposta pelo corpo da criança (com dificuldades), embora de um modo diferente da resistência oposta pela criança que - no embate entre corpo e linguagem - deixa ver pontos em que seu corpo resiste ao golpe de força (expressão usada por BERGÈS; BALBO, 2001) que, sobre ele, a palavra imprime, em alguns momentos de sua trajetória linguística (sem grandes obstáculos).

Nesse sentido, supomos que a criança autista revelaria essa resistência, por exemplo, por meio de suas manifestações ecolálicas, o que significa dizer que, pela ecolalia, ela estaria indicando seu aprisionamento aos sons da voz do outro (da voz materna). Por sua vez, supomos também que seria por meio desses sons que se poderia vislumbrar, para o autista, alguma saída. Dizendo com outras palavras - e tomando, como ponto de partida, autores como Arantes (2001) e Lier-De Vitto (2006) -, ao mesmo tempo em que a dimensão sonora da voz do outro poderia aprisionar a criança, constituindo um obstáculo ao movimento de constituição de sua subjetividade, seria por meio da dimensão sonora que se poderia indicar uma saída para esse aprisionamento, ou melhor, uma saída que permitisse uma continuação de tal movimento.

\section{O caráter estruturante da dimensão sonora da linguagem}

Com base nos autores invocados antes, podemos inferir a importância de se realçar as manifestações sonoras do corpo da criança com hipótese de autismo. Afirma Faivre-Jussiaux (1996, p. 61), referindo-se ao autismo:

\footnotetext{
Instaura-se, consequentemente, um regime dominado pelo gozo do Outro materno o qual invade o corpo do sujeito, destruindo seus limites. Ao designar o autista como 'um personagem bastante verboso', mas também como 'aquele que não chega a ouvir o que você tem a lhe dizer enquanto você se ocupa dele', Lacan insiste sobre sua relação particular com a linguagem e o Outro.
} 
Não se trata, portanto, de conceber que o autista está fora da linguagem, mas sim que ele mantém com a linguagem uma relação muito particular. A esse respeito, numa conferência em Caracas, quando questionado por Lagache sobre a questão da criança autista, Lacan (1988) respondeu que não tinha experiência com a criança autista, mas em algum lugar a língua teria acontecido nesta criança.

Assumimos, então, que, no caso do autismo, também se trataria de um embate entre corpo e linguagem, ou melhor, de uma especial resistência que o corpo opõe à linguagem. Ao que tudo indica, seria uma resistência que o corpo opõe à linguagem, pela via de uma recusa à perda/esquecimento/recalque da sonoridade da voz materna. Face a tal recusa à perda, o corpo seria invadido, inundado por essa sonoridade, deixando-se aparecer, por exemplo, através da ecolalia. Desse modo, a verbalização ecolálica do autista indicaria uma posição, por ele ocupada, em relação ao Outro primordial (a mãe).

Desde Kanner (1997[1943]), a ecolalia é concebida como a repetição em bloco de enunciados escutados pela criança em alguns momentos. Ao descrever o quadro de onze crianças por ele acompanhadas, em relação a uma delas, esse autor afirma: "Palavras fora de propósito como estas pareciam constituir sua maneira habitual de falar. Parecia repetir constantemente, como um papagaio, o que lhe havia sido dito em um momento ou outro [...] imitando inclusive sua entonação" (KANNER, 1977[1943], p. 115). Trata-se da presença maciça da voz do outro, ou melhor, da dimensão sonora dessa voz, nas verbalizações da criança, o que nos remete, portanto, à pulsão invocante, com base na proposta de Lacan (1964).

Lembremos que, na concepção freudiana, a pulsão (trieb) se situa na fronteira entre o somático e o mental, nunca se dando a conhecer por si mesma, mas apenas por meio de seus representantes. A esse respeito, Freud (1996[1905], p. 173) afirma:

\footnotetext{
Por 'pulsão' podemos entender, a princípio, apenas o representante psíquico de uma fonte endossomática de estimulação que flui continuamente, para diferenciá-la do 'estímulo' que é produzido por excitações isoladas vindas de fora. Pulsão, portanto, é um dos conceitos da delimitação entre o anímico e o físico.
}

A característica geral das pulsões seriam suas zonas erógenas localizadas na superfície do corpo, por exemplo, a pulsão escópica se localiza nos olhos, a pulsão oral, na boca. Conforme foi afirmado anteriormente, dentre as superfícies pulsionais, a boca seria considerada a mais conflituosa, uma vez que: "Boca' tanto quer dizer o que está aberto quanto o que está fechado. [...] 'Boca' mama e come, mas 'boca' trai. Ela emite 
- Ecolalia e música: a linguagem no autismo

sons, e esses sons descartam o valor alimentício do objeto: de um lado, come e, do outro, fala" (POMMIER, 2004, p. 125).

A pulsão invocante, segundo a proposta lacaniana, consiste na mais próxima da experiência do inconsciente. Ao conceber a voz como objeto $a$, Lacan (1997) afirma que ela não é assimilada, é incorporada literalmente e, como tal, está fadada ao desconhecimento. Assim, no caso da identificação da voz, "falemos de Einverleibung, de incorporação" (LACAN, 1997, p. 317, grifo nosso). Nas palavras do autor (LACAN, 1997, p. 317):

É por tudo isso, e não por outra coisa, que, desligada de nós, nossa voz aparece com um som estrangeiro. É da estrutura do Outro constituir um certo vazio, o vazio de sua falta de garantia. A verdade entra no mundo com o significante e antes de todo controle. Ela se experimenta, ela se reenvia somente por seus ecos no real. Ora, é nesse vazio que a voz, enquanto distinta das sonoridades, voz não modulada, mas articulada, ressoa.

Nessa perspectiva, na condição de objeto $a$, a voz não pode ser representada, o que significa dizer que podemos conhecer apenas seus ecos. Para Porge (2014, p. 109), "A sonorização é uma imaginarização, mais ou menos satisfatória da voz".

Didier-Weill (1999, p. 67) destaca que a forma mais primitiva de transmissão do simbólico à criança consiste na voz materna, afirmando: "na origem, a voz é pura sonoridade, para além de todo sentido".

Esse autor indica, então, a dupla face - continuidade e descontinuidade - da materialidade sonora da voz materna. Scarpa (2005, p. 26), em sua leitura, destaca a insistência desse autor "num primitivo do contínuo melódico sonoro que antecipa a segmentação, mas que não é substituído por ela".

Nas palavras de Didier Weill (1999, p. 154):

Este infans teria, assim, que encarar o fato de que a linguagem the seria transmitida como habitada por essa contradição interna: por um lado, é-lhe transmitida uma lei simbólica fundada na integração das escansões linguageiras, própria para transmitir o sentido simbólico do código; por outro lado, é-lhe transmitida ao mesmo tempo uma subversão desta lei: a pura continuidade sonora produzida pela voz dessa diva que é a mãe tende, com efeito, a abolir a descontinuidade que transmite a inteligibilidade do sentido. 
Assim, podemos dizerque, em um momento inicial na constituição da subjetividade da criança, embora convivam, na escuta do bebê, os aspectos de continuidade e descontinuidade (as escansões) da dimensão sonora da voz materna, seria a continuidade sonora que dominaria.

Segundo Vorcaro (2001), a partir da melodia que o outro lhe dirige, ele (o bebê) já experimenta a tensão da antecipação que o andamento da cantiga lhe permite supor e surpreende-se com a alteração neste andamento. Ao colocarem em discussão expressões gestuais e vocais de uma criança com diagnóstico de autismo, Vorcaro e Navegantes (2004, p. 231) referem-se a um jogo estabelecido pela analista e afirmam: "Muitos momentos de interação foram estabelecidos por meio de jogos rítmicos desse tipo em que se estabelecia a sincronia do fluxo de seu movimento a uma entonação musical ritmada por escansões e extensões sonoras".

Conforme indicam essas autoras, há um momento em que o jogo se esgota; no entanto, algo do jogo retorna. A esse respeito dizem:

\begin{abstract}
Há um funcionamento sonoro operado pela criança, em que se podem distinguir resíduos da fala do outro, seja na 'reza numérica', seja em alguns fragmentos que por vezes lhe escapam em que músicas ou falas são reconhecíveis, apesar da grande distorção. Entretanto, esses resíduos configuram-se como monólogos em que a criança parece recolher o gozo do movimento articulatório da lalação. (VORCARO; NAVEGANTES, 2004, p. 232).
\end{abstract}

Podemos dizer, então, que o resgate desses fragmentos musicais e de fala que retornam dos jogos instaurados pela analista, nas verbalizações da criança, poderia reinstaurar o movimento entre continuidade e descontinuidade temporal, ou seja, poderia esboçar cortes, rupturas na substância sonora que constitui tais verbalizações.

Sobre a relação da criança autista com a música, podemos citar ainda, como exemplo, o caso de uma menina, Elly, discutido por Maleval (2012) que faz uma análise de seu ato de cantar, aos quatro anos, a música infantil francesa Alouette, no momento em que os pais penteavam os seus cabelos após lavá-los. De acordo com as informações apresentadas por esse autor:

Alouette equivalia a all Wet (tudo molhado), palavras que aos quatro anos ela não dizia e não parecia entender. No entanto, era claro que ela havia captado os sons e estabelecido, através da música, uma relação que não podia fazer, ou não podia verbalmente. (PARK, 1972, p. 99 apud MALEVAL, 2012, p. 53). 
- Ecolalia e música: a linguagem no autismo

Destaca-se, nesse caso, não apenas a circunstância de que, pela canção, a criança envia uma mensagem aos pais, mas também e sobretudo a indicação de que a continuidade sonora (Allouette) já aponta para um corte, para uma descontinuidade (All - Ouette).

Podemos supor então que, se, em determinado momento da constituição subjetiva, há um domínio, na escuta do bebê, de uma continuidade sonora, aos poucos a descontinuidade, as escansões linguageiras vão se impondo a essa continuidade, ou melhor, nela vão provocando rupturas.

Nessa perspectiva, em relação à ecolalia no autismo, poderíamos dizer que a linearidade, a continuidade temporal tenderia a suplantar a alternância. Nesse sentido, Vorcaro (1999), seguindo a proposta lacaniana, refere-se às manifestações ecolálicas do autista como sendo blocos, ou melhor, holófrases, uma vez que, no primeiro par de significantes (S1 e S2), haveria uma colagem, não existindo intervalos entre eles. Segundo essa autora (VORCARO, 1999, p. 33): "Holófrase é, enfim, o nome que Lacan dá à ausência da dimensão metafórica. A solidificação do primeiro casal de significantes impede que um significante possa vir no lugar de outro, já que eles ocupam o mesmo lugar".

A esse respeito, a partir da proposta lacaniana, Lemos (2002, p. 51) aponta para "a possibilidade de se contrapor à holófrase, do ponto de vista psicanalítico, o fenômeno da fragmentação. Fenômeno pelo qual, ouso dizer, a criança corta a cadeia da fala da mãe e dá reconhecimento ao intervalo que lhe permite indagar sobre o desejo do Outro".

Diz Lacan (2008[1964], p. 231): "Chegaria até a formular que, quando não há intervalo entre S1 e S2, quando a primeira dupla de significantes se solidifica, se holofraseia, temos o modelo de toda uma série de casos - ainda que, em cada um, o sujeito não ocupe o mesmo lugar".

Desse modo, à luz do conceito lacaniano de holófrase, Lemos (2002) indaga sobre o enigma constituído pelos fragmentos verbais que constituem a fala inicial da criança isto é, fragmentos da fala do outro que retornam na fala infantil - que são antitéticos às manifestações verbais holofrásticas. Esse enigma, destaca a autora, diz respeito à escuta em blocos, por certos autistas, que se contrapõe à escuta, por crianças, dos intervalos da fala do outro.

Para Porge (2014), a ecolalia do autista consistiria na fixação ao momento, por ele denominado estádio de eco, que excede e precede o estádio do espelho lacaniano. Essa noção de eco foi formulada pelo autor a partir de uma discussão do mito de Echo e Narciso, da fala delirante do presidente Shereber e da noção freudiana de superego. 
Ao conceber o estádio de Eco como um momento estrutural no percurso de constituição do sujeito, Porge (2014) afirma que, nesse momento, a voz se separa do eco sonoro. Assim, o eco consiste na representação sonora da voz. Por sua vez, a voz deve ser cercada pelo silêncio, para que se constituam suas representações sonoras como, por exemplo, aquelas que são cantadas. "Entre a voz e seu eco desliza o silêncio. Se não houvesse silêncio não se ouviria o eco" (PORGE, 2014, p. 108).

Nesse sentido propõe:

\begin{abstract}
O estádio de eco estaria ligado a este momento de passagem do grito ao apelo e à fala, com a voz como objeto resto, um momento constitutivo da distinção exterior interior, correlativa de qualquer identificação e, portanto, correlativa também de uma reversão em que há um exterior do interior. A ecolalia do autista seria a fixação a esse momento que é também um momento estrutural. (PORGE, 2014, p. 122).
\end{abstract}

Desse modo, a língua se faria, inicialmente, presente nas verbalizações infantis, por meio do reflexo ou do eco da sonoridade da voz materna na escuta da criança.

Sobre o estádio de eco, poderíamos dizer que seria na passagem do grito ao apelo e à palavra que se localizaria uma especial sensibilidade da criança ao som da voz do outro, sensibilidade que, embora seja condição para o sujeito, na medida em que é um momento estrutural, deve, contudo, ser perdida para que sua estruturação aconteça sem obstáculos, conforme já foi indicado antes.

Por sua vez, se esse momento (do eco) não pôde cumprir sua função estruturante, uma vez que a criança nele ficou fixada, aprisionada, inferimos que seria por meio do próprio eco que a criança poderia sair dessa fixação, ou melhor, seria por meio do próprio eco que sua função estruturante poderia ser recuperada. Dizendo com outros termos, poderíamos localizar várias formas com que esse eco pudesse ser vivido/revivido pela criança, de modo que talvez se pudesse restabelecer, de algum modo, seu movimento estruturante.

Com fundamento no que foi explicitado, supomos, então, que manifestações musicais (por exemplo, as canções) poderiam favorecer, na criança com autismo ${ }^{4}$, a presença da musicalidade da voz materna com suas dimensões de continuidade e descontinuidade. Por sua vez, tal retorno poderia propiciar alguma ruptura na

4 Optamos por utilizar a expressão criança com autismo, em vez de criança com Transtorno do Espectro Autista (TEA) que está sendo utilizada atualmente. 
- Ecolalia e música: a linguagem no autismo

continuidade sonora incorporada por essa criança, fazendo face à resistência que seu corpo opõe à implantação do significante.

\section{Ecolalia e música: uma ilustração}

Numa tentativa de abordar empiricamente a proposta assumida neste artigo, recorreremos, apenas a título de ilustração, a fragmentos de sessões de terapia em grupo que contêm manifestações verbais de um menino que apresenta grave obstáculo em sua trajetória linguística. Esses fragmentos compõem um corpus constituído por transcrições de gravações quinzenais em vídeo das sessões - durante o período de dois meses e dez dias - e por anotações de observações da terapeuta que realizou as filmagens e da mãe do menino. As sessões ocorreram em uma instituição pública especializada no atendimento a autistas, na cidade onde mora a criança focalizada - de agora em diante, nomeada $B^{5}$ - que foi encaminhada à instituição com o diagnóstico de transtorno difuso do desenvolvimento, por um psiquiatra infantil, dando início a tratamento individual e em grupo. As filmagens e transcrições foram realizadas por uma das terapeutas dessa instituição - de agora em diante, nomeada F - que nos cedeu o corpus $^{6}$ de onde foram retirados os episódios discutidos mais adiante, nos quais estão presentes, além de $B$, duas crianças (W e Fg) e três terapeutas (A, F e R).

Para nos aproximarmos do caso em foco, consideramos importante, antes da abordagem dos episódios selecionados, transcrever alguns fragmentos de fala da mãe de B, conforme se seguem: "[...] Com um ano e três meses de idade, ele levou uma grave queimadura na mão com o ferro de passar roupa" [...]. "Depois da queimadura, ele deixou de dizer algumas palavras que já tinha adquirido, só permanecendo 'papa'". Desde os dois anos de idade, "não sabia pedir água, chamar 'mamãe' e nem as outras pessoas e objetos pelo nome adequado. Voltou a falar as primeiras palavras com três anos e meio. Fala bastante de forma incompreensível [...]". "Ele está dando para falar pela televisão, imitando as frases que ouve. Um dia, eu o vi falando todo o comercial de televisão... entretanto, quando ele me viu, parou e saiu andando". "[...] Não olha para as pessoas e não dá atenção a nada". "Ele só gosta de brincar só. Parece que ninguém pode brincar com ele. Se alguém se aproxima, ele sai de perto, para de brincar". "[...] Ele é bastante ligado em TV ... as pessoas o chamam e ele nem dá atenção. Eu o levei ao otorrino e não

5 Para nomear o adolescente, extraímos a primeira letra de Binho, nome fictício que lhe foi atribuído pela terapeuta.

6 Convém notar que esse corpus fez parte da tese de Doutorado de Andrade (2005). 
foi detectado nenhum problema de audição". A mãe de B informa ainda que ele é uma criança violenta, bate nas pessoas, morde e, às vezes, parece chorar sem motivo aparente. No entanto, gosta de música e, segundo F, quando a mãe canta, ele reage cantando e se aproxima dela. De acordo com observações de F, em alguns momentos, o menino parece falar para si mesmo, ficando de costas para as pessoas.

Passando aos episódios, a fim de facilitar a visualização e a discussão das manifestações verbais de $B$, selecionamos duas sessões de gravação ${ }^{7}$ - sessão 1 e sessão 2, por ordem cronológica - que foram registradas com um intervalo de 14 dias entre elas. Nessas sessões, B tinha, respectivamente, dez anos e dois dias de idade e dez anos e 16 dias de idade. Como a transcrição completa dessas sessões ocuparia um grande espaço ${ }^{8}$, o que não caberia em um artigo, recortamos os fragmentos mais diretamente relacionados aos aspectos que serão aqui discutidos, servindo-Ihes de ilustração, em consonância com nossos objetivos. Tais fragmentos serão, então, tratados como episódios, sendo referidos à sessão em que aparecem. Por sua vez, a numeração dos episódios não obedecerá, necessariamente, a uma ordem cronológica. Os participantes serão nomeados como se segue:

$\mathrm{B}=$ Binho

W=Willian e Fg=Fagner ${ }^{9}$

A=Terapeuta 1

$\mathrm{F}=$ Terapeuta 2

$\mathrm{R}=$ Terapeuta 3

De início, convém destacar que as manifestações verbais de B trazem a marca da ecolalia, uma vez que o menino, em vários momentos, repete, de forma imediata ou mediata, a fala da terapeuta, mantendo, por vezes, o tom ou a entonação dessa fala, conforme mostram os seguintes episódios:

\section{Episódio 1 - Sessão 1}

(B participa de brincadeira de trem)

$[\ldots]$

\footnotetext{
7 Foram escolhidas essas duas sessões, porque nelas aparece, de forma dominante, uma canção - o trenzinho - frequentemente cantada pelo grupo em uma brincadeira de trem.

8 Ver Andrade (2005).

9 Nome fictício de crianças que participam das sessões de terapia em grupo.
} 
- Ecolalia e música: a linguagem no autismo

F - Esse trem tá muito rápido!

$\mathrm{R}$ - ...é o trem bala!

B - Esse trem tá rápido (fala de uma forma lenta)

F - Esse trem tá rápido demais!

B - Rápido demais! (mesma entonação)

$[\ldots]$

\section{Episódio 2 - Sessão 1}

(B contorna uma grande mesa seguido por $F$ e termina pisando no pé de A)

$[\ldots]$

A - Você pisou no meu pé!

B - (Fala algo incompreensível)

A - Isso é muito chato!

B - Isso é muito chato!

A - E agora deu pra repetir as coisas, foi?

$[\ldots]$

No entanto, uma leitura/escuta mais acurada do corpus de que dispomos nos indicou que, em meio à ecolalia, algumas produções verbais de B se submetiam a um intenso movimento, sobre o qual pretendemos nos debruçar.

Primeiramente, destacamos duas expressões que se repetem, insistentemente, nas sessões de gravação recortadas: Estação Cempi e Maquinista Cuqui que exemplificamos por meio de três episódios:

\section{Episódio 3 - Sessão 1}

(B participa de brincadeira de trem)

$[\ldots]$

B - Estação Cempi

R - Vamos para estação Cempi, ouviu, Ana, o que Binho disse!

B - Es-ta-ção Cem-pi! 
B - Ceeeempi! Ceeeempi!

R - Oh Binho vai atrás de Willian!

B - Estação Cempi

$[\ldots]$

\section{Episódio 4 - Sessão 2}

$[\ldots]$

(B coloca a mão no ouvido, aproximando-se do armário)

B - Maquinista cuqui!

(Fg retira a bola do armário. B fica olhando os movimentos de Fg com a bola)

F - Pois é, tu tá... tu tá se lembrando, né Binho, daquela brincadeira...!

(B contorna a grande mesa, acompanhando o movimento de Fg com a bola)

B - E viva o maquinista cuqui!

$\mathrm{F}-\ldots$ do trem!

$[\ldots]$

\section{Episódio 5 - Sessão 2}

(B e F estão brincando de jogar bola)

$[\ldots]$

F- Opa!

(B arremessa a bola de volta para F dizendo:)

B - Maquinista Cuqui!

F- Cuqui!

Maquinista Cuqui

$[\ldots]$

Dessas expressões (Estação Cempi e Maquinista Cuqui), os termos estação e maquinista pertencem a uma canção ${ }^{10}$ - $O$ trenzinho - frequentemente cantada em

\footnotetext{
10 A canção O trenzinho é cantada pelo grupo com os seguintes termos, havendo variações: Lá na estação/Bem de manhãzinha/ Passa um trenzinho/Todo enfileirado/E o maquinista puxa a manivela/ Piuí, tá-tá-tá/ Cuidado, maquinista/Pra não sair do trilho, maquinista/Maquinista, olhe a pista/Não é de borracha.
} 
- Ecolalia e música: a linguagem no autismo

uma brincadeira de que participa o grupo de crianças a que B pertence e as terapeutas responsáveis pelo grupo. Nessa brincadeira, ao mesmo tempo em que cantam, crianças e terapeutas se colocam em fila com a ajuda de uma corda, percorrendo vários locais da Instituição. Por sua vez, o termo Cempi nomeia a Instituição-locus da pesquisa, sendo Cuqui um termo inventado pelo menino. É importante notar, contudo, que, apesar da repetição insistente dessas expressões, os termos Cempi e Cuqui são, constantemente, substituídos por outras palavras. Em relação ao primeiro termo, recortamos um exemplo:

\section{Episódio 6 - Sessão 2}

(Os meninos, por sugestão de F, escrevem os nomes das estações em uma página em branco, antes da brincadeira de trem):

$[\ldots]$

F - Qual é a outra estação?

W - Ah Prazeres!

F - Prazeres! E a outra?

W - Aeroporto!

B - Prazeres, não, é CEMPI (olhando para o papel)

É Cempi Pô!!! (olhando para F)

Es-ta-ção La-bo-ra-tó-rio!!!

$\mathrm{F}$ - Ah, tem o laboratório, Binho, também?

(Fg fica caminhando, do fundo da sala para o portão de entrada, várias vezes seguidas)

B - Es-ta-ção Psi-qui-a-tra!!

F - Pois é, tem outra também! Olha só quantas tem!

B - Estação Psiqui!

$[\ldots]$

\section{Episódio 7 - Sessão 2}

$[\ldots]$

(B termina de escrever "Cempi" e grita) 
B - Es-ta-ção Cem-pi!!!

(Fernanda se aproxima dele e olha para a página)

F - Deixa eu ver! Muito bem! Faça a outra agora! Escreve a outra, agora!

W - Estação Prazeres!

B - Estação Chiqui!

F - Vai, escreve aí, agora!

(F lhe dá uma outra página)

B - Chiqui!

$[\ldots]$

Destaca-se, portanto, um movimento na expressão recorrente - Estação $\underline{X}$ em que se abre um lugar $(\underline{X})$, pelo qual passam vários termos, o que nos indicou o caráter móvel de manifestações verbais do menino. No entanto, o que nos deixou, especialmente, surpresas, no que toca essas manifestações, foi o intenso movimento a que se submeteu o termo Cuqui, ou melhor, foram as várias transformações nele ocorridas, dando lugar a diferentes termos, embora se mantendo, entre eles, uma aproximação sonora. Essas transformações tornam-se, portanto, visíveis, conforme exemplificam os episódios que se seguem:

\section{Episódio 8 - Sessão 1}

(B participa de brincadeira de trem):

$[\ldots]$

A - Cuidado, maquinista!

B - Batuque!

A - Pra não sair do trilho, maquinista!

W - (Fala algo ininteligível)

B - Pra não sair do trilho, maquinista!

Batuque!

$[\ldots]$ 
- Ecolalia e música: a linguagem no autismo

\section{Episódio 9 - Sessão 1}

$[\ldots]$

( Na brincadeira de trem, B segura a cintura de A, olhando para ela e dizendo):

B - Maquinista ruqui!

A - Maquinista puqui, olhe a pista! Maquinista puqui, olhe a pista, olhe a pista!

$[\ldots]$

\section{Episódio 10 - Sessão 1: (B participa de brincadeira de trem)}

$[\ldots]$

A - Maquinista, maquinista, olhe a pista!

B - Maquinista puqui, puqui, puqui!

A - Olhe a pista, não é de borracha!

$[\ldots]$

\section{Episódio 11 - Sessão 1}

$[\ldots]$

(Na brincadeira de trem, B olha na direção da câmera):

A - Maquinista, maquinista...!

B - Uuqui! Uqui!

A - Uuqui! Uuuuuuuuiiiiiiii!

$[\ldots]$

Episódio 12 - Sessão 2

$[\ldots]$

(B pega uma peça de madeira - com letras -, em cima da mesa):

F - Vai, Binho, escreve!

B - Estação a maquinista Cuqui! (sorri, olhando para F)

F - Vá lá, escreve aí! 
W - Escreve: preso!

B - Cu cu!

$[\ldots]$

Assim, a partir do recorte do termo insistente cuqui - que, primeiramente, ressoou em nossa escuta - e seguindo, em cada uma das sessões, uma leitura/escuta tanto proativa quanto retroativa, isto é, considerando as verbalizações do menino tanto posteriores, quanto anteriores ao aparecimento desse termo, ficamos surpresas com as semelhanças sonoras que ele mantinha com vários outros termos, como é o caso de: batuque, ruqui, puquil $^{71}$, uqui, cucu, chiqui, caqui. Nesses casos, a escuta de alguns segmentos sonoros comuns nos permitiu agrupar essas produções verbais em torno de cuqui que, por sua vez, remeteu-nos, também por alguma semelhança sonora, ao termo ux $^{12}$ da canção O trenzinho. Parece importante destacar as produções Chiqui e caqui, para tecermos algumas considerações suplementares. A primeira, ao que parece, teria resultado de uma modificação sonora de cuqui, no episódio 7 (B - Estação Chiqui), indicando um cruzamento entre as expressões (Maquinista X e Estação X) e deixando mais visível ainda a mobilidade sonora, em torno dessa produção (cuqui), nas verbalizações do menino. No que concerne à segunda (caqui) - também uma modificação sonora de cuqui -, transcrevemos o fragmento em que ela surgiu:

\section{Episódio 13 - Sessão 2}

$[\ldots]$

(B contorna a grande mesa, indo para o fundo da sala e parando na quina da parede)

F - Quê que a gente vai brincar, hoje, hein?

(B abre a janela da sala).

B - Quê a gente vai brincar qui, caqui, hoje?

$\mathrm{F}-\mathrm{O}$ quê?

B - O quê?

$[\ldots]$

11 Convém notar que Maquinista puqui foi, primeiramente, produzido por A (episódio 9).

12 Estamos nos referindo a certa semelhança sonora entre os morfemas iniciais das duas palavras: cuqui e puxa. 
- Ecolalia e música: a linguagem no autismo

Pareceu-nos então relevante, tanto o aparecimento de caqui no meio de uma verbalização ecolálica, quanto o fato de ter convocado, em nossa escuta, uma semelhança sonora com a expressão tá aqui, produzida por B (e pelas terapeutas), conforme mostram os episódios:

\section{Episódio 14 - Sessão 1}

(B participa de brincadeira de trem)

$[\ldots]$

A - Estamos passando...

B - Cempi!

A - Cempi! Cempi! Cadê a estação Cempi?

B - Tá aqui!

$[\ldots]$

\section{Episódio 15 - Sessão 2}

$[\ldots]$

(B se dirige à porta do pátio)

F - Fernando?

B - Não tá aquiiii!

$[\ldots]$

\section{Episódio 16 - Sessão 2}

$[\ldots]$

(F vai para o armário)

F - Oxe, cadê a chave?

(B responde sem nem procurá-la)

B - Tá aqui

$[\ldots]$

Com fundamento no que foi apresentado, confrontamo-nos, então, com as ressonâncias provocadas pelo grupo sonoro cuqui. Em outras palavras, esse grupo sonoro 
parece localizar-se em um ponto de cruzamento entre vários grupos sonoros semelhantes que podem ser concebidos como efeitos de ecos ou de ressonâncias de uns sobre outros. Nessa espécie de rede sonora, associações homofônicas produziram visíveis modificações no caráter ecolálico de verbalizações de B, indicando cortes, rupturas nessas verbalizações. Relembrando Porge (2014), diríamos que a ecolalia seria um efeito do aprisionamento ao eco; no entanto, por mais paradoxal que pareça, seria por meio do eco que se poderia vislumbrar alguma mobilidade nas manifestações verbais do autista, apontando para uma saída desse aprisionamento. Convém, entretanto, notar que, no caso de $B$, essa mobilidade se mostrou de forma pontual, na medida em que, constantemente, alternava-se com a dimensão de rigidez verbal. Nesse caso, talvez pudéssemos supor uma singular mudança de posição do menino em relação à fixidez, à imobilidade verbal, marca que se tem, comumente, atribuído à ecolalia no autismo.

\section{A título de conclusão}

Retomando o que foi afirmado na Introdução deste artigo, assumimos a proposta de que as manifestações ecolálicas de crianças com autismo indicariam um aprisionamento à dimensão sonora, à música da voz materna, o que ofereceria resistência à implantação do significante em seu corpo. Por sua vez, supusemos também que o confronto da criança com a música da voz materna, através de outros meios de expressão, como é o caso da canção, poderia, de algum modo, fazer face a essa resistência.

Nessa perspectiva, a presença marcante da ecolalia, nas manifestações verbais de $B$, seria concebida como sinais de uma resistência ou recusa do menino a uma perda da sonoridade da voz materna, conforme as propostas de Lemos (2008) e de Balbo (2004).

No entanto, é importante lembrar que nos surpreendemos com os ecos (PORGE, 2014) que ressoam de um grupo sonoro a outro, nas verbalizações da criança, fazendonos apreender um movimento singular nessas verbalizações. Assim, adquiriram especial destaque, em nossa escuta, as expressões Estação Cempi e Maquinista Cuqui das quais os termos iniciais (Estação e Maquinista) teriam deslizado de uma canção frequentemente presente em brincadeira do grupo de que B faz parte. Assim, essas expressões, especificamente o grupo sonoro Cuqui, pareceram ecoar uma variedade de grupos sonoros, indicando, portanto, nesses grupos, um intenso movimento que se pode denominar jogos sonoros ou jogos de ressonância. 
- Ecolalia e música: a linguagem no autismo

Para finalizar, propomos que essa discussão forneceu algumas indicações de que crianças - e adolescentes - com hipótese de autismo, por algum motivo, teriam ficado presas à pura sonoridade da voz materna, ou melhor, teriam se recusado a perder essa sonoridade, formando-se um obstáculo a seu movimento de constituição subjetiva. Nessa perspectiva, supomos também, com fundamento em Didier-Weill (1999), que, através da música, poderia se abrir para o autista uma porta de acesso ao significante. Dizendo de outro modo, supomos que a dimensão sonora/a musicalidade da voz materna, ao se fazer presente através de outros meios de expressão - como, por exemplo, a canção proporcionaria à criança uma possibilidade de saída de seu aprisionamento ao som, o que significaria uma possibilidade de se confrontar com a resistência que seu corpo opõe à perda desse som, podendo talvez continuar pela via de constituição de sua subjetividade.

Agradecimentos: Dirigimos nossos especiais agradecimentos a Fernanda Wanderley Correia de Andrade que nos cedeu o corpus de B do qual extraímos as ilustrações deste artigo.

\section{Referências}

ANDRADE, F. W. C. Brilhando através das nuvens negras: há subjetividade na linguagem da criança autista? 2005. 421 f. Tese (Doutorado em Psicologia Cognitiva) - Universidade Federal de Pernambuco, Recife, 2005.

ARANTES, L. As múltiplas faces da especularidade. Letras de Hoje, n. 36, v. 3, p. 253-259, 2001.

BALBO, G. A língua nos causa. In: VORCARO, A. (Org.). Quem fala na língua: sobre as psicopatologias da fala. Salvador: Ágalma, 2004. p. 123-150.

BERGÈS, J. ; BALBO, G. A atualidade das teorias sexuais infantis. Porto Alegre: CMC Editora, 2001.

CARVALHO, G. M. M. O ritmo como questão nas manifestações verbais singulares do autista. Revista Latinoamericana de Psicopatologia Fundamental, n. 4, v. 15, p. 781-797, 2012.

DIDIER WEILL, A. Invocações: Dionísio, Moisés, São Paulo e Freud. Rio de Janeiro: Companhia de Freud, 1999. 
FREUD, S. Três ensaios sobre a teoria da sexualidade. In: STRACHEY, J. (Ed.). Edição Standard Brasileira das Obras Psicológicas Completas de Sigmund Freud. v. 7. Rio de Janeiro: Imago, 1996[1905].

FRAIVRE-JUSSIAUX, M. Autismo infantil. In:KAUFMANN, P.(Ed.). Dicionário enciclopédico de psicanálise: o legado de Freud a Lacan. Rio de Janeiro: Jorge Zahar Editor, 1996. p. 5663.

KANNER, L. Os distúrbios autísticos de contato afetivo. In: ROCHA, P. S. (Org.). Autismos. São Paulo: Editora Escuta, 1997[1943]. p. 111-170.

LACAN, J. Intervenciones y textos. Buenos Aires: Editora Manancial, 1988.

Seminaire XI: les quatre concepts fondamentaux de la psychanalyse. Texte établi par Jacques Allan Miller. Paris: Éditions du Seuil, 1964.

. O Seminário: a angústia (1962-1963). Recife: Publicação não comercial do Centro de Estudos Freudianos do Recife - CEF, 1997.

Escritos. Rio de Janeiro: Jorge Zahar Editor, 1998.

O Seminário 11: os quatro conceitos fundamentais da psicanálise. Rio de Janeiro: Jorge Zahar Editor,2008[1964].

LEITE, N. V. A. Riso e rubor: para falar do corpolinguagem. In: LEITE, N. V. A. (Org.) Corpolinguagem: gestos e afetos. Campinas: Mercado de Letras, 2003. p. 81-92.

LEMOS, C. T. G. Da Angústia na infância. Revista Literal, n. 10, p. 117-126, 2008. Sobre fragmentos e holófrases. In: Psicanálise, infância, educação. Anais do III Colóquio do LEPSI. São Paulo: Universidade de São Paulo, 2002. p. 45-52.

LIER-DE VITTO, M. F. Patologias de linguagem: sobre as vicissitudes de falas sintomáticas. In: LIER-DE VITTO, M. F.; ARANTES, L. (Orgs.). Aquisição, Patologia e Clínica de Linguagem. São Paulo: Ed. PUC, 2006. p. 183-200.

MALEVAL, J.-C. Língua verbosa, língua factual e frases espontâneas nos autistas. In: MURTA, A.; CALMON, A.; ROSA, M. Autismo(s) e atualidade: uma leitura lacaniana. Belo Horizonte: Scriptum, 2012. p. 45-70. 
- Ecolalia e música: a linguagem no autismo

POMMIER, G. Da passagem literal do objeto ao moedor do significante. In: MELMAN, C. et al. (Orgs.). O significante, a letra e o objeto. Rio de Janeiro: Companhia de Freud, 2004. p. 119-126.

PORGE, E. Voz do eco. Campinas: Mercado de Letras, 2014.

SCARPA, E. M. A criança e a prosódia: uma retrospectiva e novos desenvolvimentos. Cadernos de Estudos Linguísticos, n. 47, v. 1, p. 19-17, 2005.

VIVÈS, J-M. A voz na clínica psicanalítica. Rio de Janeiro: Contra Capa/Corpo Freudiano, 2012.

VORCARO, A. Crianças na Psicanálise: clínica, instituição, laço social. Rio de Janeiro: Companhia de Freud, 1999.

. O organismo e a linguagem maternante: hipótese de trabalho sobre as condições do advento da fala e seus sintomas. Trabalho apresentado no Congresso Internacional de Psicanálise e Clínica de Bebês, Curitiba-PR, 2001.

VORCARO, A.; NAVEGANTES, L. F. A ecorporação de uma voz. In: VORCARO, A. (Org.). Quem fala na língua: sobre as psicopatologias na fala. Salvador: Ágalma, 2004. p. 229245.

COMO CITAR ESTE ARTIGO: CARVALHO, Glória Maria Monteiro de; MELO, Maria de Fátima Vilar de. Ecolalia e música: a linguagem no autismo. Revista do GEL, v. 15, n. 1, p. 63-84, 2018. Disponível em: https://revistadogel.gel.org.br/.

DOI: http://dx.doi.org/10.21165/gel.v15i1.1813

Submetido em: 06/04/2017. | Aceito em: 05/03/2018. 